\title{
Recurrent Marginal Zone Lymphoma
}

National Cancer Institute

\section{Source}

National Cancer Institute. Recurrent Marginal Zone Lymphoma. NCI Thesaurus. Code C68684.

The reemergence of marginal zone lymphoma after a period of remission. 